\title{
Farmers' Perceived Vulnerability and Proactive versus Reactive Climate Change Adaptation in Chile's Maule Region
}

\author{
Alejandra Engler ${ }^{1,2}\left(\mathbb{D}\right.$, Marieke L. Rotman $^{3}$ and P. Marijn Poortvliet ${ }^{3, *(D)}$ \\ 1 Department of Agricultural Economics, Pontificia Universidad Católica de Chile, \\ Avenida Vicuña Mackenna 4686, Santiago 8330024, Chile; mengler@uc.cl \\ 2 Nucleo Milenio Center CESIEP, Talca 3460000, Chile \\ 3 Sub-Department Communication, Philosophy \& Technology, Wageningen University, \\ 6700 EW Wageningen, The Netherlands; marieke.rotman@wur.nl \\ * Correspondence: marijn.poortvliet@wur.nl
}

Citation: Engler, A.; Rotman, M.L.; Poortvliet, P.M. Farmers' Perceived Vulnerability and Proactive versus Reactive Climate Change Adaptation in Chile's Maule Region.

Sustainability 2021, 13, 9907. https:// doi.org/10.3390/su13179907

Academic Editors: Rhys Manners and Irene Blanco-Gutiérrez

Received: 29 July 2021

Accepted: 31 August 2021

Published: 3 September 2021

Publisher's Note: MDPI stays neutral with regard to jurisdictional claims in published maps and institutional affiliations.

Copyright: (c) 2021 by the authors. Licensee MDPI, Basel, Switzerland. This article is an open access article distributed under the terms and conditions of the Creative Commons Attribution (CC BY) license (https:// creativecommons.org/licenses/by/ $4.0 /)$.

\begin{abstract}
Changes in climatic conditions are unavoidable and irreversible and an early and effective adaptation in farming systems will be vital for resilient agriculture. Although the extant literature has described factors that explain climate change adaptation, the roles of proactive versus reactive adaptation related to perceived vulnerability are still underexplored. The aim of our study was to open a new angle of discussion by linking farmers' perceptions of vulnerability with their adaptation response, and exploring the dynamic of such a relationship. Semi-structured interviews with farmers were held in the Maule Region of central Chile $(n=36)$. The interview included questions o about main agricultural challenges, perceptions of climate change and its impact, adaptation strategies, and perceptions of vulnerability, exposure, sensitivity, and ability to adapt. In order to interpret the interview data, a content analysis procedure was followed. The results indicate that farmers respond differently by either engaging in proactive or reactive adaptation behavior. Furthermore, the patterns of either proactive or reactive adaptation behavior can be explained by structural factors and social and human capital. While structural factors, such as production systems and financial capital, explain engaging in adaptation to climate change, social and human capital act as enhancing factors that explain proactive adaptation. Future policies on adaptation behavior should focus on promoting proactive forms of adaptation behavior by developing and enhancing social connections and access to information, as well as on the provision of financial schemes to enable efficient and effective adaptation within the agricultural sector.
\end{abstract}

Keywords: climate change; perceived vulnerability; proactive adaptation; reactive adaptation; agricultural systems; farming practices

\section{Introduction}

The most recent report of the Intergovernmental Panel on Climate Change (IPCC) projects an increase of at least 1.5 degrees in global temperatures between 2030 and 2052 [1], a decrease in water availability, and a higher occurrence of extreme weather events that will reshape conditions for agricultural systems and challenge food security [1-4]. To some extent, changes in climate are unavoidable and irreversible [1]. Hence, early and effective adaptation in farming systems to new climatic circumstances will be vital for resilient agriculture (e.g., [5]), and even more so in vulnerable areas [6,7]. However, several barriers abound that are related to socio-economic contexts and culture and that preclude or restrain adaptation [8-11]. Moreover, the lack of awareness of climate change for farmers in some vulnerable rural regions-including parts of Southeast Asia, Africa, and Latin Americamakes adaptation less likely [2,12,13]. Perceptions regarding climate change have been typically used to explain adaptation [14-16]. However, we posit that adaptation to climate change can be shaped in proactive and reactive ways, responding to how individual 
farmers perceive their vulnerability, and it is contingent upon the structural and social context surrounding the farm and the farmer.

The focus of this research was on farmers' individual experiences regarding vulnerability and adaptation processes in central Chile's Maule region using a qualitative study. Although a broad scope of literature exists regarding research on the factors that influence adaptation (e.g., [9,17-19], less has been written regarding proactive and reactive adaptation behavior, and, to the best of our knowledge, the patterns behind different adaptation strategies and perceived vulnerability have remained relatively underexplored. The aim of our study was to open a new angle of discussion by linking farmers' perceptions of vulnerability with their adaptation responses, and exploring the dynamic of such a relationship. The objective of this paper is twofold. First, we describe how farmers perceive their vulnerability to climate change and the adaptive measures they take. Second, we explore structural and social factors that may underlie the dynamic relationship between perceived vulnerability and proactive and reactive forms of adaptation.

We conducted a qualitative case study in the Maule Region of central Chile. This is a prime agricultural producing region in the country; its production system focuses primarily on orchards and vineyards. Importantly, the Maule Region has experienced major droughts over the last decade and it is expected that for the second half of the century, precipitations will continue to drop by $40 \%$ [20]. The study area is located in the Maule Region that contains a large number of small-scale farmers with the highest rural population, and therefore, this area is considered particularly vulnerable to climate change [21,22]. Chile's government is currently creating and implementing adaptation plans for different regions at a large scale [21]. However, we argue that it is equally important to focus on adaptation strategies at the individual level, as the effectiveness of adaptation options crucially depends on many factors specifically related to farmers' idiosyncratic circumstances, including location, implementation costs, and crop type [12,23].

This paper is organized as follows. In Section 2, we provide a background for our fieldwork. We first discuss adaptation strategies, perceived vulnerability, and adaptation behavior. Then we elaborate on the role of socio-demographics and physical, human, and social capital, followed by the proposed research framework. Section 3 describes the methods and data analysis, Section 4 presents the results, and Section 5 offer the discussion and conclusion, respectively.

\section{Theoretical Background}

\subsection{Adaptation to Climate Change}

Although there is not a single definition of adaptation or adaptation behavior to climate change, we paraphrase it as the "adjustment of production strategies or practices to reduce, protect and resist hazards" [14,24-26], and in this regard, the literature offers a diverse portfolio of adaptation strategies and practices. Among them, the most cited include changing the timing of sowing and harvesting, changing crops, adopting efficient irrigation technology, implementing new technologies for climate control, and relocating businesses (e.g., [6,11,27]). Further adaptation strategies have been classified as different types. For example, Robert [24] provides a classification using timing, temporal, and spatial scopes, in which the timing scope encompasses reactive (response after the shock) versus proactive (anticipatory) adaptation, the temporal scope encompasses strategic (long-term adjustments) and tactical (short-term adjustments), and, finally, the spatial scope encompasses localized (single crop) and widespread (farm system) adaptation. Zilberman et al. [26] approached adaptation by identifying incremental versus transformative adaptation, and reactive versus proactive adaptation. Although distinguishing characteristics of adaptation strategies and practices can derive different classifications, the most used in the literature on climate change is reactive versus proactive, where reactive adaptation occurs after the negative effects of climate change are already experienced, while proactive adaptation is aimed at staying ahead of possible climate change damage to the farm (e.g., $[2,15-17,28-30])$. Despite the agreement regarding the definition of reactive 
and proactive adaptation, the practices and strategies included in each one vary depending on the case study. For example, the widely used practice of "changing the timing of sowing and harvesting" has been classified as proactive and reactive by different scholars depending on local conditions and farming systems [30,31], and, as pointed out by Carman and Zint [14], a strategy or measure could be both, depending on if it is a response (reactive) or if it a coping mechanism (proactive).

\subsection{Vulnerability to Climate Change and Adaptation}

IPCC defines vulnerability as "the propensity or predisposition to be adversely affected" [32], which entails the degree to which a system is susceptible to adverse effects, the function of the magnitude and rate of climate variation, and the sensitivity and adaptive capacity of the system, resulting in a multidimensional concept that bridges biophysical and social aspects [33-35]. Several studies have proposed indicators to measure vulnerability, including location, socio-demographic aspects, and physical, social, human, and natural capital as the main components of exposure, sensitivity, and adaptive capacity, with the aim of identifying key components of vulnerability and/or relating it to adaptation behavior [34-40]. Nevertheless, in the literature, increasing attention has been given to perceived vulnerability and awareness of climate change [33,41,42], as it has been demonstrated that there is a strong link between perceptions and adaptation [11,14-16,43-46]. Likewise, the relationship between perceived vulnerability and bio-physical data has also been studied and it was concluded that there is a positive trend between them [42,47]. However, there is also evidence of an underestimation of bio-physical vulnerability and how it is affected by social, psychological, and demographic variables. For example, Christian et al. [42] analyzed the underestimation of vulnerability by using a case study on the perceived vulnerability of farmers to floods in Ghana. They concluded that gender, education, and source of information are key variables in explaining the gap. Hence, considering perceived vulnerability is important in understanding the adaptation process and, therefore, for providing effective policies to increase adaptation.

Perceived vulnerability and awareness to climate change and adaptation behavior have been successfully explored in the literature using different approaches (e.g., $[16,46,48,49]$ ). For one thing, awareness, meaning knowledge and perceptions about changes in climatic variables, has been proved to be related to the adoption of adaptation strategies [41,50]. Furthermore, perceptions vary across regions, but within a region, individuals also have different perceptions mostly related to their educational level, experience, age, personal beliefs, and so on $[33,41,42,50,51]$. Regarding perceived vulnerability, the protection motivation theory (PMT) and variations of the model have been used to capture perceived vulnerability $[16,44-46,48,49]$. PMT states that a person's appraisal of a threat, that is, the feeling of vulnerability, and the motivation to protect oneself, that is, adaptation behavior, are based on four factors: (1) the perceived severity of the situation, (2) the susceptibility to it, (3) the perceived effectiveness of the available adaptation practices and technologies, (4) and whether one thinks they will able to adapt. In comparing PMT vis-à-vis the definition of vulnerability, we highlight some similar characteristics. The severity of the situation can be compared to the exposure of the system, susceptibility to sensitivity, perceived effectiveness, and the ability to adapt to adaptive capacity.

\subsection{Structural and Social Factors Explaining Adaptation}

Besides perceptions of climate change and vulnerability, socio-demographic variables, and social, physical, human, and natural endowments, along with farm structural variables, have also been used to explain adaptation to climate change [15,16,52]. Knowledge, either collected through (formal) education or study can broaden the perceived ability to adapt, the perceived effectiveness of the available coping response, and the self-efficacy of farmers $[16,41,50]$. Moreover, experience influences the perceived vulnerability and adaptation behavior, as it implies a learning process $[15,28,30,53]$. Physical endowment 
and credit access constitute critical constraints to adaptation [54-56] and make farmers more vulnerable in their ability to cope with climate change.

Finally, the role of a farmer's social capital has been described by Engler et al. [9]; connecting with a social network is important for the adoption of adaptation measures. Social capital opens access to information and resources, leading to a greater ability to adapt. It has been shown that access to reliable information on weather and climate change influences perceived vulnerability and adaptation behavior $[9,11,45,52,57,58]$.

\subsection{Proposed Study Approach}

The key element described above was used to conduct a case study focused on the relationship between perceived vulnerability and reactive and proactive adaptation strategies. In doing so, we narrowed in on the directionality between vulnerability and adaptation, and on the roles of socio-demographic, economic, and psychological factors. First, differentiating between reactive and proactive types of adaptation is key in understanding adaptation behavior among farmers. Second, following the literature, we believe that perceived vulnerability is pivotal in how farmers adjust to climate change and that the feedback between adaptation and perceived vulnerability can become either a virtuous or a vicious cycle. Finally, previous studies suggest that socio-demographic, economic, and psychological factors are relevant in explaining adaptation. However, less has been said about the moderating role that these factors may play between vulnerability and adaptation-a void we aim to fill.

The objective of the present research was to explore the relationship between farmers' individual experiences regarding vulnerability and agricultural adaptation processes in Chile's Maule region. To this end, in Section 2, we described the key elements that were used to achieve our objectives. We narrowed in on the directionality between vulnerability and adaptation, and the role that socio-demographic, economic, and psychological factors play in it. In doing so, we first describe how farmers perceive their vulnerability to climate change and the challenges climate change presents to them. Second, we present the reactive and proactive adaptation practices used by the farmers, and third, in Section 5, we explore structural and social factors that may underlie the dynamic relationship between perceived vulnerability and proactive and reactive forms of adaptation.

\section{Method}

In this study, in-depth interviews were conducted to gain an understanding of the perceptions farmers have concerning their vulnerability and adaptation decisions, as well as their restrictions to adaptation.

\subsection{Research Site}

Interviews were conducted in the Maule Region in Chile (see Figure 1), characterized by the highest (32\%) rural population in Chile, along with the Araucanía region, and an agricultural gross domestic product (GDP) that contributes 13.3\% to the total regional GDP.

The Maule Region covers $9.4 \%$ of the total cultivated land across the country, of which orchards and vineyards are the main production activities [22]. The area has a Mediterranean climate, with a six-month dry period from September through February and a rainy winter, and is also characterized by the presence of microclimates, causing weather patterns that vary from location to location. Given this heterogeneity, the area is very suitable as a research location [59]. Projections for 2050 in this area are an average $2.1^{\circ} \mathrm{C}$ rise in summer temperatures and $1.5^{\circ} \mathrm{C}$ in winter temperatures, with annual rainfall decreasing by $16 \%$ [21]. The specific sites for the research were the direct surroundings of the Maule River - the communes of Linares, Parral, San Javier, Pencahue, San Clemente, and Talca (see Figure 2). 


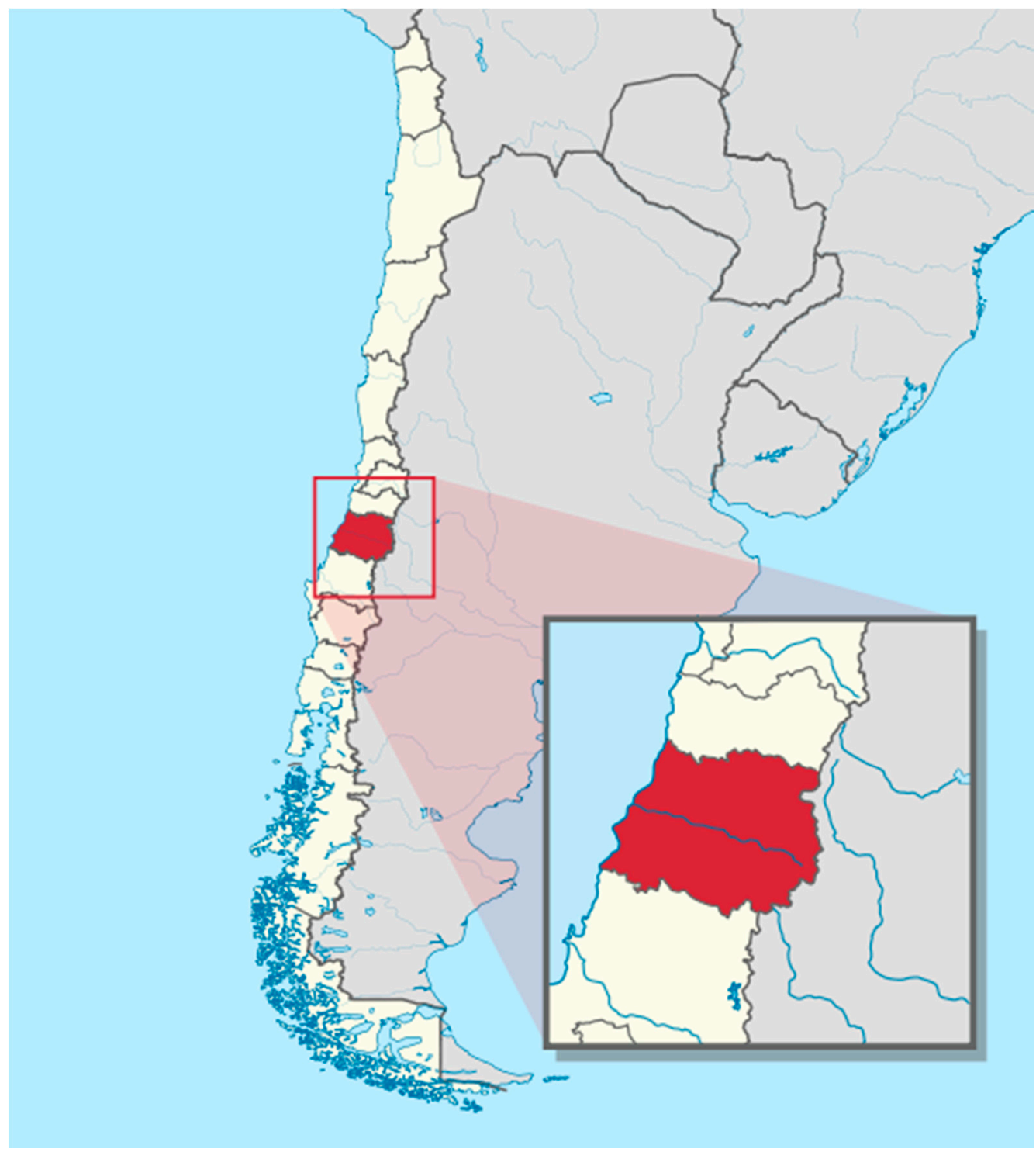

Figure 1. Location of the Maule Region (in red) within Chile (in beige). (Image source: TUBS, CC BY-SA 3.0 https: // creativecommons.org/licenses/by-sa/3.0, via Wikimedia Commons (accessed on 16 August 2021).

\subsection{Participants}

The interviewees were 36 farmers that were selected from a database of a previous study conducted in the Maule Region. This previous study included a sample of 400 observations. The selection of the 36 farmers in the current research from the primary database was purposive, with an attempt to include a diverse set of farmers in terms of crop type, farm size, and location who were available and willing to participate. The farmers interviewed for this study $(n=36)$ worked in farms ranging in size from 0.25 ha to 1200 ha, and amongst the crops cultivated were wheat, maize, fruits, vineyards, pasture, and rice. The sample was composed of six women and thirty men, and the mean age was 52.8 years (standard deviation $=15.2$ years).

The interviews were conducted on-site between November and December 2018 and lasted between 30 and $70 \mathrm{~min}$. One pilot interview was conducted to test the outline, after which some minor adjustments were made. The data of this pilot was included in the results, as this interview provided useful information. 


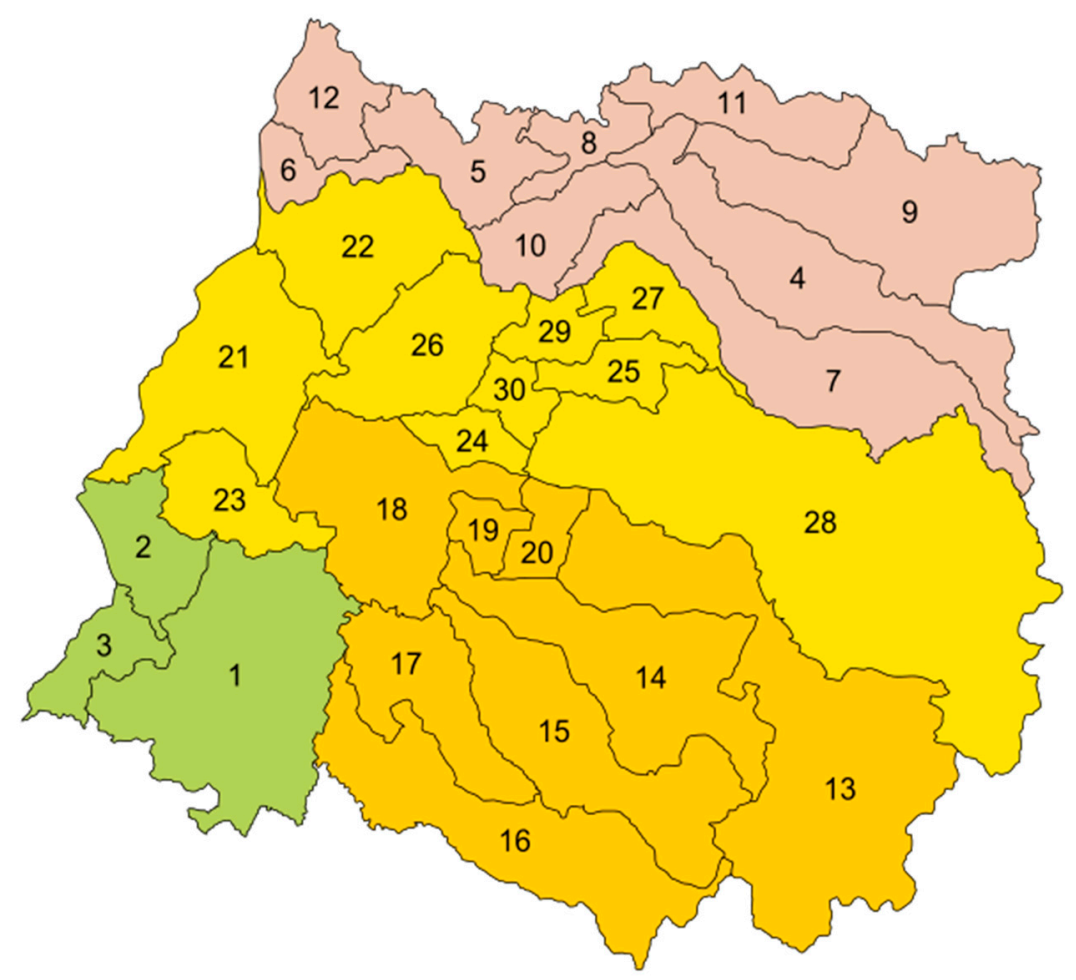

Figure 2. Communes located within the four provinces of the Maule Region (pink = Curicó; yellow $=$ Talca; orange $=$ Linares; light green $=$ Cauquenes $)$. Interviews were conducted in communes of Linares (14), Parral (16), San Javier (18), Pencahue (26), San Clemente (28), and Talca (30). (Image source: Jlechuga86, CC BY 3.0 https:/ / creativecommons.org/licenses/by/3.0, via Wikimedia Commons (accessed on 16 August 2021).

\subsection{Interview Procedure}

Semi-structured interviews were conducted by the second author and a translator using an interview protocol to ensure uniformity amongst all interviews. All interviews were recorded and transcribed for further analysis. The protocol contained detailed instructions in English and Spanish for starting, asking them open-ended questions, and ending the interview. Part of the protocol included signed informed consent of the farmers interviewed. The interview was designed to understand farmers' perceptions on climate change, vulnerability, and adaptation. With the aim of identifying relations between these core concepts and important related factors, the interview included questions on (1) main agricultural challenges, (2) perception on climate change and its impact, (3) adaptation strategies, and (4) perceptions of vulnerability, exposure, sensitivity, and ability to adapt.

In order to elaborate more on the perceived relationship between vulnerability and adaptation, a visual exercise was done at the end of the interview with 17 of the interviewees. In this visual exercise, the farmer was presented with two cards-one with the statement "I feel vulnerable", the other with the word "adaptation". The farmers were asked to place an arrow in the direction that they felt was right, from vulnerability to adaptation, from adaptation to vulnerability, or both ways. Next, the farmer was presented with several cards with factors that, during the study, had come up as important-social connections, knowledge, financial means, crop type, insecurity, and information.

\subsection{Analyses}

Interviews were transcribed in Spanish by a Chilean Spanish native speaker. In order to interpret the data from the 36 interviews, a content analysis procedure described by Berg [60] was performed. First, conceptual categories were formed inductively based on the research questions in the outline as described above. General challenges in agriculture, experienced climate change, consequences of climate change, vulnerability, and adaptation 
were used and divided into subthemes. The responses were coded by hand using these categories and by inductively forming new categories. The analysis was performed in Atlas.ti (version 1.5.4).

For the coding, as a primary step, we divided the transcripts into five categories using the sections of the questionnaire, namely (a) general challenges in agriculture, (b) perceptions regarding climate change, (c) consequences of climate change, (d) perceived vulnerability, and (e) adaptation to climate change. Using the first nine interviews, the categories were divided manually into sub-themes according to keywords using Berg's rule of "three mentions is a pattern", resulting in 39 subthemes. The coding was included in Atlas.ti to process the remaining interviews.

\section{Results}

\subsection{Perceptions of Climate Change and Challenges}

Without exception, in all 36 interviews, farmers perceived changes in weather in the last few years, which was expressed in changes related to (a) the period of the seasons, mostly late summers and winters, (b) precipitation patterns, (c) temperatures, and (d) occurrence of extreme weather events (mainly hail). These led to a number of challenges, namely (1) productivity loss, (2) increasing occurrence of pests and diseases and related cost management, and (3) conflicts due to scarcity of water.

The variability of weather patterns challenges the management of productive activities such as sowing, harvesting, and irrigation planning, as one of the interviewees mentioned, "... the uncertainty about the climate, how will it be [during the season], this is why you do not know when to sow or to plant,... you do not know if it is going to hail, or rain or not rain" (Farmer \#25). Additionally, unexpected weather events may cause significant damage that is hard to prevent. "... [This season] we had perfect cherries in Rancagua, San Fernando, Rengo, but those are all gone [as a consequence of the hail]... I believe that the hail was something nobody was expecting, nobody had anticipated." (Farmer \#12).

A second challenging consequence of the changing climate is the higher incidence of pests, diseases, and fungi, which flourish in the hot and humid climate. In total, 13 farmers mentioned problems related to this: "The heat [is the hardest to deal with], because if you use [plastic] foil for your plants [plastic in agriculture is used to create conditions to control for weather events and keep humidity in the plant], after a rain, this transforms into a greenhouse that increases the incidence of fungi and bacteria. There are chemicals for that but ... they are expensive." (Farmer \#32). The above also implies higher management costs: "Before this [climate change] potatoes was one of the strongest crop, almost nothing [no fertilizers or fungicides or pesticides] needed to be applied, now we have to apply a lot of fungicide for the little birds [aphids]" (Farmer \#32).

The trend of fewer precipitations also threatens a water shortage that could lead to another challenge. In the area under study, it seems to be still a long way off but is becoming a reality as a water shortage continues, as pointed out by a farmer: "There is going to be a fight over water, a chaos, and there are things that are going to happen that no one could not even think of. This is going to be a war for water, because everyone will want to survive" (Farmer \#36). The consequences of changing weather patterns leave the farmers no choice but to adjust their sowing dates, which affects not only productivity but also might affect market prices: "In comparison to other years, melons were planted on October 10th, and this year we planted the 1st of November, 3 weeks delay for harvesting is too much, the prices drop ..." (Farmer \#15).

Climate change is a source of concern that make farmers feel more vulnerable and engage in a challenge to survive: "I do not know how far we can go if the weather continues like this, because behind us, there is a family, and we have to keep working, and fighting the climate, because we cannot stay with crossed arms" (Farmer \#22). Another interviewee mentioned, "I feel that we are in a transition, what is happening now will get worse in the future. Also, farming generates a negative impact on the environment and the business is not very competitive, for large farmers and for medium and smallholders". 


\subsection{Perceived Vulnerability, Proactive and Reactive Adaptation}

"One has to adapt, one is compelled to adapt ... . if the farmer does not change and does not adapt to what comes, no, no [it will go wrong]. But unfortunately, one has to wait until it happens [changes in climate], it is more reactive; one cannot make changes before ... because of economic constraints ... this is a business and one has to see the impact first" (Farmer \#14). This farmer recognized the vulnerability to climate change and also makes an important distinction-proactive versus reactive adaptation. As for reactive adaptation, different adaptation measures were implemented by the farmers. The most common reactive adaptation was a change in sowing and harvesting dates (mentioned 21 out of 36 times). This change in dates is an unavoidable consequence of the changing seasons and weather patterns. In the same direction, the increase in pests and diseases due to heat and humidity drives the use of more pesticides and fertilizers, which was also often mentioned as an adaptation measure. One farmer mentioned, "No, in my case, there is not much adaptation; if I see something wrong [with the crop], I consult with the specialist and add more fertilizers or pesticides". (Farmer \# 1). Another farmer also engages in reactive adaptation: "We have been adapting labor dates. For crops, we look for the best moment to work [sow and harvest]".

In contrast, we also observed more proactive adaptation patterns, such as diversification, which was most frequently mentioned by the farmers in the sample, which allows for spreading the risk in case the harvest of one crop type fails. A large farmer mentioned, "We planted five hectares-three at the beginning, and then two of clonal plants. They were very expensive, but with that experiment, we realized that the latter was able to resist better the adverse condition that we had in the field" (Farmer \#8). A variation on this was switching to more resistant crops. One of the interviewees relayed how he sees the future in terms of changing crops and the displacement of farming activities: " .. then we have to think well about the crop that you will grow in your area, everything you see will be displaced to the south [of Chile]; before you would not think to see fruit orchards in the south, now you can find them." (Farmer \#25). Likewise, another chosen strategy is the use of improved seed or varieties for annual crops, orchards, and vineyards. For example, a farmer mentioned how he had switched to a more low-risk, new variety of rice, which is sown in "dry" ground instead of underwater: "One can sow [the new variety of rice] in September [before traditional varieties]; this variety is easier" (Farmer \#29). Another mentioned, "... [due to climate change] we are more exposed, but we have been working since 2002-2003 in improving genetic aspects, we asked incubators to provide us with clonal plants that are supposed to be stronger... " (Farmer \#8). Irrigation technology and machinery were also mentioned as adaptation strategies. Regarding irrigation technology one farmer mentioned, " ... this has been the most important effect of climate change [water scarcity]; we are trying to prevent and anticipate dry seasons, investing in irrigation technologies to cover that" (Farmer \# 8).

However, it should be pointed out that these investments are often not (yet) within reach of the smaller farmers with less financial capital. "[I have] not too much [pressurized irrigation], because the technology is expensive. Before, there was a water channel that I used to water my tomatoes, now you need to have drip irrigation, and how much you think it costs..?" (Farmer \#17). As for the first point, governmental institutions try to make it more accessible by giving out subsidies: "Now I invested in irrigation system for corn through INDAP,_sprinkler irrigation, it is called" (Farmer \#19), but it should be noted that farmers are not always eligible for subsidies.

The most radical "adaptation measure" mentioned was quitting farming altogether. Although this is a very far-reaching measure, many farmers mentioned at least doubts about the future of their enterprise. One farmer had even decided already to not sow this year: "Yes [I believe the best option] is closing the door, but not forever, there is always hope. If they [the buyers] tell next year that there will be seedbed cultivation ...., then we will return to cultivating, but only with the guarantee of a contract" (Farmer \#5).

As explained in the methodology, to gain a more comprehensive view of the relationship between vulnerability and adaptation, we performed a visualization exercise. The 
main results can be summarized in the perception of causality between vulnerability and adaptation and the most relevant factors affecting them. First of all, it became clear that farmers perceive a different causality between both concepts. Seven farmers indicated that vulnerability influences adaptation: "First, one feels vulnerable because one does not know what will come, and then one adapts" (Farmer \#31). In contrast, eight farmers felt it was the other way around, that adaptation influences vulnerability: "No, one has to adapt first, it is preventive. It's the same as for the treatments of the bees [beekeeper], it has to be preventing" (Farmer \#28). Interestingly, two farmers indicated that they felt the relationship actually worked both ways.

\subsection{Structural Factors, Human, and Social Capital}

\subsubsection{Structural and Economic Factors}

Of the structural and economic factors, we found that productive systems, financial capital, and governmental aid were the most relevant factors in shaping adaptation processes. The production system and crops also proved to be dominant themes in the interviews and were mentioned several times. The crops or farming systems were, in most cases, related to sensitivity. For example, cattle production was mentioned as less risky and adaptable to climatic variability compared to annual crops and orchards. The effects of climate change on crops also vary and are most commonly related to higher incidence rates of pests and diseases and lower productivity due to scarcity of water. In this regard, one interviewee mentioned, "For vegetables, there is not too much [impact of] change [in climate], but those who have orchards were affected. Last night I saw the news of hail, this does affect vegetables; pests affect us more, but we can fight it" (Farmer \#1).

Financial capital has been also mentioned as a relevant factor that prevents adaptation, as mentioned by one farmer when asked about investments for adaptation: "Feeling vulnerable is like the scale [of the farm], if I have more resources than my neighbor, he is more worried than me, because at least I have some tools or capital" (Farmer \#36). In the literature, farm size is conventionally used as a proxy for financial capital. Small farmers also struggled with not being able to compete, which makes adaptation less profitable. In their words, small farmers cannot compete with larger farmers, which have higher production and a greater ability to negotiate prices.

In the same vein, governmental support that comes through different institutions provides means to promote adaptation. Different forms of state support, mainly INDAP (Instituto de Desarollo Agrupecaurio) and PRODESAL (Programa de Desarollo Local), provide extensions, credits, and subsidies for specific agricultural activities to smallholders. Less assistance is available to medium and large farmers; however, specific incentives for irrigation and soil conservation are also available to them through SAG (Servicio Agrícola y Ganadero) and CNR (Comisión Nacional de Riego). One of the farmers shares his experience: "Through INDAP we receive knowledge, information, and resources that help to make the change [to adapt to climate change] less costly, because one lacks information and all that kind of things" (Farmer \#23); another voiced "The advisors [the technical advisors from PRODESAL] always come because they are thoughtful of us, and they [the help] give us [loan] \$100,000 [Chilean pesos] per year to buy supplies, it's like a help: I have to put 30,000 [of my own money] and [I can] make the purchase for 130,000 [with the help of PRODESAL]" (Farmer \#30).

We found that farmers feel generally supported by governmental organizations in terms of financial means, social connections, information, and advice. However, other farmers were less enthusiastic: "[I feel] alone, the corresponding governmental entity does not give you advice or answers your questions. The governmental entity, like INDAP, does not provide information about meetings if you are not connected to a group with an extension worker that charges you an amount of pesos for a visit. If you are not informed, they do not inform you of anything" (Farmer \#32). 


\subsubsection{Human and Social Capital}

As for human capital, experience was important for many farmers, as nine of them explicitly highlighted it. Most farmers had worked many years in agriculture and gained most of their knowledge from experience. Experience allows for acknowledging the threat: "The change we've noticed has been very fast, as I'm quite old already, I remember that we did not worry about the weather before [ ... I I've been feeling it stronger since about 20 years ago. But this last year it has been even more, and they say it's going to be worse" (Farmer \#21). Experience could also help farmers feel less vulnerable: "Insecurity is not [an important factor to me], I have experience and I feel sure of what I do even if I go backwards and forwards [in business success]" (Farmer \#21). However, some farmers also mentioned that experience may have a reverse effect on proactive adaptation. As mentioned by some of the farmers, the longer farmers had been practicing agriculture, the less inclined they seemed to change something in their business, leaving them more vulnerable. "This area is stuck in monoculture. The old ones [farmers] plant what they plant, just that, and I always heard that the most important thing is rotation of crops" (Farmer \#20). In conclusion, experience can help farmers to feel less vulnerable because they trust in their own knowledge, but might work counterproductively, as more experienced farmers seem to be less open to innovation and new insights, which might withhold adaptation behavior.

Social connections were important for many farmers, often linked to sharing information, knowledge, and experiences with their neighbors and colleagues. The innovations of one farmer seem to have a reinforcing effect on his or her neighbors if they are in frequent contact. Social networks enable access to information, advice, and other means, as mentioned by one farmer: "Two years ago, a group set up a committee, from which we receive technical assistance, advised me, and then this group also applied for [a subsidy] for machinery. They applied through INDAP, and INDAP made a contribution" (Farmer \#29). Access to information is vital in the process of adaptation. This may encompass information on the weather, projections for the future, and information on adaptation practices and technologies. Out of the 36 farmers interviewed, at least 14 farmers stated that they actively stay informed through various information sources like TV, the internet, social media, and newspapers. The quality of the information is important. Many farmers stated that their main sources of information were other farmers, neighbors or friends, either through casual contacts or organized groups: "We have a guide group, PRODESAL, and they give us the information for everything in agriculture, the times of sowing, the types of sowing at the date when you have to do it, and for us, it is important to feel less vulnerable" (Farmer \#26). Farmers also reported that important sources of information are newspapers and social media: "One sees the forecast for a year, always the television says "this year will be rainy" or "it will rain in spring". This year they said it was going to be cold, and it was cold, so what did I do? I went and bought a lot of heating, my heating is wood, and it went great, I was not vulnerable to the cold, because I adapted before, prevented before" (Farmer \#35).

Farmers explained that social networks not only provide access to information but allow for exchanging solutions, which helped them to feel more capable of taking action. Furthermore, cooperating with neighbors was inevitable as a consequence of climate change, as one of the farmers from the drier regions explained: "Yes, more than once it happened to us [that there was not enough water], you had to reach agreements with the neighbors to be able [to irrigate], or water at night, sometimes we irrigated all night, because the neighbor said: "Neighbor, I will lend you the water but it has to be at night, because at 07:00 in the morning I am going to use it" (Farmer \#12). As observed, social connections seemed to generally promote proactive adaptation, as they can increase perceived exposure and sensitivity, as well as the ability to adapt through sharing information, knowledge, and experiences.

\section{Conclusions and Discussion}

The current study set out to investigate the relationship between perceived vulnerability to climate change and farmers' proactive and reactive types of adaptation by uncovering the farmers' perspectives of the role or roles of vulnerability in adaptation as well as their 
driving factors. Following the analyses, we highlight three main conclusions that allowed us to set up a framework to understand the complexity of the patterns behind different adaptation strategies and perceived vulnerability (Figure 3).

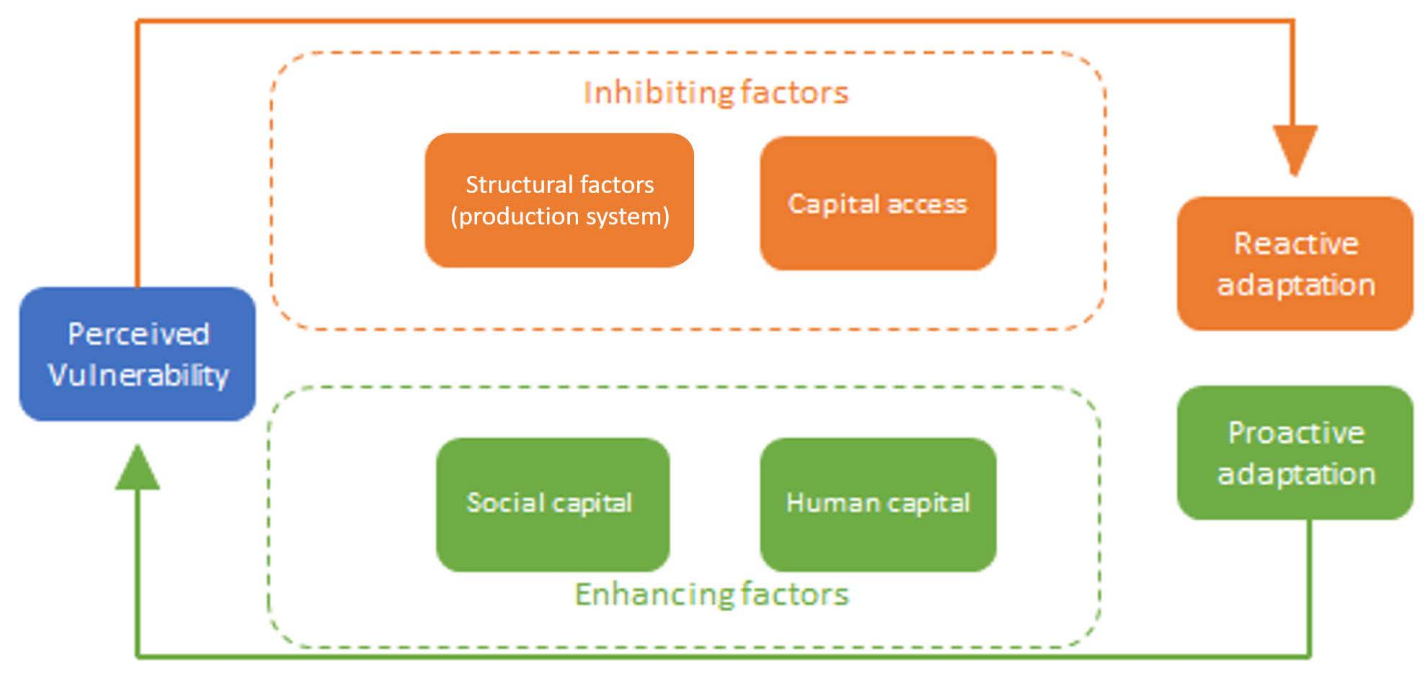

Figure 3. Proposed relationships between perceived vulnerability and reactive adaptation (upper pathway, orange arrow) and proactive adaptation (lower pathway, green arrow), and their associated inhibiting and enhancing factors.

Firstly, among the proactive strategies, we found that the most used were diversification of the productive system, the use of improved varieties of plants and seeds, and adoption of irrigation technology, which, as Robert et al. [24] pointed out, are part of a dynamic process aimed at minimizing vulnerability. As for reactive adaptation patterns, changes in growing seasons (sowing and harvesting) and the use of pesticides and fertilizers were the most common to avoid the short-term impact of climate variability. Our conclusions regarding the main adaptation strategies are in line with those from previous studies, although we should note that other studies have used their own classifications, and not all practices have been categorized in a similar fashion. The most notable is changing the dates of sowing and harvesting, which has been classified in some studies as proactive adaptation [15,61-63]; however, we followed the responses of our interviewees, who describe it as a reactive action. This result could also be an indication that farmers' perspectives regarding adaptation are different from what mainstream research has considered in previous studies, and that more attention needs to be paid to the motivations behind different types of adaptation.

Second, even though the literature on reactive and proactive adaptation makes the connection to vulnerability $[30,50,64-66]$, the bi-directional relationship that we present in our findings is not typically acknowledged, as previous work focuses on just one of the adaptation patterns. In addition, from the visual exercise, we observed an interesting view of the relationship between vulnerability and proactive and reactive adaptation-a relationship that we depict in Figure 3. We found two groups of farmers; the first one exhibited a more reactive mode of adaptation and was linked to a perception that vulnerability leads to adaptation. In sharp contrast, the second group described their motivation to adapt as more preventive and, in this case, the direction is opposite-adaptation leads to (lower) vulnerability. It is, therefore, important to further narrow in on how these two groups experience the influence of different factors stimulating or inhibiting proactive adaptation behavior.

The third conclusion that can be derived from our study is how different factors explaining adaptation are related to the directionality of vulnerability and adaptation. Typically, adaptation strategies or measures have been studied in light of driving factors or stressors $[8-10,63,65,67]$. We went further in identifying which factors relate to reactive 
and proactive adaptation. In Figure 3, we depict the observation that farmers who are reactive in response to climatic events attributed more importance to crop type (possibly influencing if adaptation is possible, effective, and affordable), financial means, and access to information as inhibiting factors. The factors mentioned here are clearly related to constraints, which mark a lower ability to adapt. In turn, social connections, experience, and knowledge are highly typical of proactive farmers and were found to have a relation with lower perceived vulnerability (e.g., [68]). In fact, social connections were the most frequently mentioned driver of engaging in proactive adaptation. In this sense, when farmers share experiences with others, they can learn from the negative effects of climate change even before it affects them. Access to information was also highly valued by all farmers. However, this factor works out differently for proactive and reactive adaptation. As explained before, reactive behavior is associated with low access to information, which leads to higher vulnerability; proactive behavior is enhanced by access to information, leading to adaptation.

This study has also limitations that invite further analysis. First, it is based on an exploratory field study intended to sketch out the mechanisms that connect perceived vulnerability with proactive and reactive adaptation. Hence, it is not meant to be representative, and a more extensive and quantitative study may provide more insights into possible cyclical processes between adaptation and perceived vulnerability that our results tentatively suggest. Second, our study did not include any "hard measures" of biophysical or agronomic indicators-it relied purely on (self-reported) perceptions. It would be relevant to further analyze the possible gap between perceived and biophysical indicators of vulnerability - for instance, farmers' experienced vulnerability versus agronomic measures-and see how this gap could explain reactive versus proactive on-farm decisions.

While this is an exploratory study, the results shed light on the relationship between perceived vulnerability and adaptation to climate change. This merits discussion of some policy implications. For one thing, financial constraints may inhibit proactive adaptation; however, financial capital was not found to be an enhancing factor. In sharp contrast, access to information and social connections appear to be key enhancing factors. For supporting agricultural producers, policymakers should be mindful of the social and human factors, for example, of structural barriers that could lead a farmer (to believe they are) locked in and have no alternative to resorting to reactive adaptation or quitting farming altogether.

Author Contributions: Conceptualization, A.E., M.L.R., P.M.P.; methodology, A.E., M.L.R., P.M.P.; data analysis, A.E., M.L.R., P.M.P.; writing—original draft preparation, A.E., M.L.R., P.M.P.; writingreview and editing, A.E., P.M.P.; visualization, A.E., P.M.P.; supervision, A.E., P.M.P.; project administration, A.E., P.M.P.; funding acquisition, A.E., P.M.P. All authors have read and agreed to the published version of the manuscript.

Funding: This work was supported by the FONDECYT program, Chile, through Project Grant Number 1180556.

Institutional Review Board Statement: The study was conducted according to the guidelines of the Declaration of Helsinki.

Informed Consent Statement: Informed consent was obtained from all participants involved in the study.

Data Availability Statement: Data available upon request due to restrictions regarding the privacy of the respondents.

Conflicts of Interest: The authors declare no conflict of interest.

\section{References}

1. IPCC. Summary for Policymakers. In Global Warming of $1.5^{\circ} \mathrm{C}$; An IPCC Special Report on the impacts of global warming of $1.5^{\circ} \mathrm{C}$ above pre-industrial levels and related global greenhouse gas emission pathways, in the context of strengthening the global response to the threat of climate change, sustainable development, and efforts to eradicate poverty; Masson-Delmotte, V., Ed.; World Meteorological Organization: Geneva, Switzerland, 2018. 
2. Howden, S.M.; Soussana, J.F.; Tubiello, F.N.; Chhetri, N.; Dunlop, M.; Meinke, H. Adapting agriculture to climate change. Proc. Natl. Acad. Sci. USA 2007, 104, 19691-19696. [CrossRef]

3. Mertz, O.; Mbow, C.; Reenberg, A.; Diouf, A. Farmers' perceptions of climate change and agricultural adaptation strategies in rural Sahel. Environ. Manag. 2008, 43, 804-816. [CrossRef] [PubMed]

4. Schmidhuber, J.; Tubiello, F.N. Global food security under climate change. Proc. Natl. Acad. Sci. USA 2007, 104, 19703-19708. [CrossRef]

5. Tittonell, P. Assessing resilience and adaptability in agroecological transitions. Agr. Syst. 2020, 184, 102862. [CrossRef]

6. FAO. Tracking Adaptation in Agricultural Sectors: Climate Change Adaptation Indicators. 2017. Available online: http: //www.fao.org/3/i8145e/i8145e.pdf (accessed on 2 September 2021).

7. IPCC. Climate Change 2007: Impacts, Adaptation and Vulnerability. Intergovernmental Panel on Climate Change Fourth Assessment Report; IPCC: Geneva, Switzerland, 2007.

8. Chen, H.; Wang, J.; Huang, J. Policy support, social capital, and farmers' adaptation to drought in China. Glob. Environ. Chang. 2014, 24, 193-202. [CrossRef]

9. Engler, A.; Jara-Rojas, R.; Bopp, C. Efficient use of water resources in vineyards: A recursive joint estimation for the adoption of irrigation technology and scheduling. Water Resour. Manag. 2016, 30, 5369-5383. [CrossRef]

10. Handschuch, C.; Wollni, M. Improved production systems for traditional food crops: The case of finger millet in western Kenya. Food Secur. 2016, 8, 783-797. [CrossRef]

11. Roco, L.; Engler, A.; Bravo-Ureta, B.; Jara-Rojas, R. Farm level adaptation decisions to face climatic change and variability: Evidence from Central Chile. Environ. Sci. Policy 2014, 44, 86-96. [CrossRef]

12. Dasgupta, P.; Morton, J.F.; Dodman, D.; Karapinar, B.; Meza, F.; Rivera-Ferre, M.G.; Vincent, K.E. Rural areas. In Climate Change 2014: Impacts, Adaptation, and Vulnerability. Part A: Global and Sectoral Aspects. Contribution of Working Group II to the Fifth Assessment Report of the Intergovernmental Panel on Climate Change; Field, C.B., Barros, V.R., Dokken, D.J., Mach, K.J., Mastrandrea, M.D., Chatterjee, S.M.M., Ebi, K.L., Estrada, Y.O., Genova, R.C., Girma, B., Eds.; Cambridge University Press: Cambridge, UK; New York, NY, USA, 2014; p. 613. [CrossRef]

13. Tambo, J.A.; Abdoulaye, T. Climate change and agricultural technology adoption: The case of drought tolerant maize in rural Nigeria. Mitig. Adapt. Strateg. Glob. Chang. 2012, 17, 277-292. [CrossRef]

14. Carman, J.; Zint, M.T. Defining and classifying personal and household climate change adaptation behaviors. Glob. Environ. Chang. 2020, 61, 102062. [CrossRef]

15. Deuffic, P.; Garms, M.; He, J.; Brahic, E.; Yang, H.; Mayer, M. Forest Dieback, a Tangible Proof of Climate Change? A CrossComparison of Forest Stakeholders' Perceptions and Strategies in the Mountain Forests of Europe and China. Environ. Manag. 2020, 66, 858-872. [CrossRef]

16. Grothmann, T.; Patt, A. Adaptive capacity and human cognition: The process of individual adaptation to climate change. Glob. Environ. Chang. 2005, 15, 199-213. [CrossRef]

17. Adger, W.N.; Dessai, S.; Goulden, M.; Hulme, M.; Lorenzoni, I.; Nelson, D.R.; Anita, J.W. Are there social limits to adaptation to climate change? Clim. Chang. 2009, 93, 335-354. [CrossRef]

18. Arbuckle, J.G.; Morton, L.W.; Hobbs, J. Farmer beliefs and concerns about climate change and attitudes toward adaptation and mitigation: Evidence from Iowa. Clim. Chang. 2013, 118, 551-563. [CrossRef]

19. Arbuckle, J.G.; Prokopy, L.S.; Haigh, T.; Hobbs, J.; Knoot, T.; Knutson, C.; Widhalm, M. Climate change beliefs, concerns, and attitudes toward adaptation and mitigation among farmers in the Midwestern United States. Clim. Chang. 2013, 117, 943-950. [CrossRef]

20. Garreaud, R.; Boisier, J.P.; Rondanelli, R.; Montecinos, A.; Sepúlveda, H.; Veloso-Águila, D. The Central Chile Mega Drought (2010-2018): A Climate dynamics perspective. Int. J. Climatol. 2019, 40, 421-439. [CrossRef]

21. De Cambio Climatico, O.; del Medio Ambiente, M. Plan Nacional de Adaptación al Cambio Climático. 2014. Available online: http:/ / www.a2c2.utalca.cl/docs/documentos/PAN-web2.pdf (accessed on 2 August 2020).

22. ODEPA. Chilean Agriculture Overview. 2017. Available online: https://www.odepa.gob.cl/wp-content/uploads/2017/12/ panoramaFinal20102017Web.pdf (accessed on 2 August 2020).

23. Engler, A.; Poortvliet, P.M.; Klerkx, L. Toward understanding conservation behavior in agriculture as a dynamic and mutually responsive process between individuals and the social system. J. Soil Water Conserv. 2019, 74, 74A-80A. [CrossRef]

24. Robert, M.; Thomas, A.; Bergez, J.E. Processes of adaptation in farm decision-making models: A review. Agron. Sustain. Dev. 2016, 36, 64. [CrossRef]

25. UNFCCC. Adoption of the Paris Agreement. Paris Agreement text English. 2015. Available online: https://unfccc.int/sites/ default/files/english_paris_agreement.pdf (accessed on 2 August 2020).

26. Zilberman, D.; Zhao, J.; Heiman, A. Adoption versus Adaptation, with emphasis on climate change. Annu. Rev. Resour. Econ. 2012, 4, 27-206. [CrossRef]

27. Schilling, J.; Freier, K.P.; Hertig, E.; Scheffran, J. Climate change, vulnerability and adaptation in North Africa with focus on Morocco. Agric. Ecosyst. Environ. 2012, 156, 12-26. [CrossRef]

28. Cruz, G.; Baethgen, W.; Bartaburu, D.; Bidegain, M.; Giménez, A.; Methol, M.; Morales, H.; Picasso, V.; Podestá, G.; Taddei, R.; et al. Thirty Years of Multilevel Processes for Adaptation of Livestock Production to Droughts in Uruguay. Am. Meteorol. Soc. 2018, 10, 59-74. [CrossRef] 
29. Repetto, R. The Climate Crisis and the Adaptation Myth. EliScolar-A Digital Platform for Scholarly Publishing at Yale. 2008. Available online: https:/ / elischolar.library.yale.edu/cgi/viewcontent.cgi?article=1019\&context=fes-pubs (accessed on 2 August 2020).

30. Roche, L. Adaptive rangeland decision-making and coping with drought. Sustainability 2016, 8, 1334. [CrossRef]

31. Duy Minh, D.; Dan Hao, N.; Lebailly, P. Adapting to Climate Extreme Events Based on Livelihood Strategies: Evidence from Rural Areas in Thua Thien Hue Province, Vietnam. Sustainability 2020, 12, 10498. [CrossRef]

32. IPCC. Annex II: Glossary. 2014. Available online: https://archive.ipcc.ch/pdf/assessment-report/ar5/syr/AR5_SYR_FINAL_ Annexes.pdf (accessed on 2 September 2021).

33. Darabant, A.; Habermann, B.; Sisay, K.; Thurnher, C.; Worku, Y.; Damtew, S.; Lindtner, M.; Burrell, L.; Abiyu, A. Farmers' perceptions and matching climate records jointly explain adaptation responses in four communities around Lake Tana, Ethiopia. Clim. Chang. 2020, 163, 481-497. [CrossRef]

34. Jamschidi, O.; Asadi, A.; Kalantari, K.; Azadi, H.; Scheffran, J. Vulnerability to climate change of smallholder farmers in the Hamadan province, Iran. Clim. Chang. Manag. 2019, 23, 146-159. [CrossRef]

35. Singh, S. Bridging the gap between biophysical and social vulnerability in rural India: A community livelihood vulnerability approach. Area Dev. Policy 2020, 5, 390-411. [CrossRef]

36. Malherbe, W.; Sauer, W.; Aswani, S. Social capital reduces vulnerability in rural coastal communities of Solomon Islands. Ocean Coast. Manag. 2020, 191, 105186. [CrossRef]

37. Mortreux, C.; O'Neill, S.; Barnett, J. Between adaptive capacity and action: New insights into climate change adaptation at the household scale. Environ. Res. Lett. 2020, 15, 074035. [CrossRef]

38. Pahm, N.T.T.; Nong, D.; Sathyan, A.R.; Garschagen, M. Vulnerability assessment of households to flash floods and landslides in the poor upland regions of Vietnam. Clim. Risk Manag. 2020, 28, 100215. [CrossRef]

39. Tran, D.D.; Quang, C.N.X.; Duy Tien, P.; Tran, G.; Long, P.K.; Van Hoa, H.; Giang, N.N.H.; Thu Ha, L.T. Livelihood Vulnerability and Adaptation Capacity of Rice Farmers under Climate Change and Environmental Pressure on the Vietnam Mekong Delta Floodplains. Water 2020, 12, 1328. [CrossRef]

40. Wichern, J.; Descheemaeker, K.; Giller, K.E.; Ebanyat, P.; Taulya, G.; van Wijk, M.T. Vulnerability and adaptation options to climate change for rural livelihoods-A country-wide analysis for Uganda. Agric. Syst. 2019, 176, 102663. [CrossRef]

41. Alam, G.M.; Alam, K.; Mushtak, S. Climate change perceptions and local adaptation strategies of hazard-prone rural households in Bangladesh. Clim. Risk Manag. 2017, 17, 52-63. [CrossRef]

42. Christian, A.K.; Dovie, B.D.; Akpalu, W.; Codjoe, S.N.A. Households' socio-demographic characteristics, perceived and underestimated vulnerability to floods and related risk reduction in Ghana. Urban Clim. 2021, 35, 100759. [CrossRef]

43. Arbuckle, J.G.; Morton, L.W.; Hobbs, J. Understanding farmer perspectives on climate change adaptation and mitigation: The roles of trust in sources of climate information, climate change beliefs, and perceived risk. Environ. Behav. 2015, 47, 205-234. [CrossRef]

44. Frank, E.; Eakin, H.; Ló Pez-Carr, D. Social identity, perception and motivation in adaptation to climate risk in the coffee sector of Chiapas, Mexico. Glob. Environ. Chang. 2010, 21, 66-76. [CrossRef]

45. Osberghaus, D.; Finkel, E.; Pohl, M. Individual adaptation to climate change: The role of information and perceived risk. ZEW-Cent. Eur. Econ. Res. Discuss. Pap. 2010, 10-061. [CrossRef]

46. Truelove, H.B.; Carrico, A.R.; Thabrew, L. A socio-psychological model for analyzing climate change adaptation: A case study of Sri Lankan paddy farmers. Glob. Environ. Chang. 2015, 31, 85-97. [CrossRef]

47. Thaker, J.; Smith, N.; Leiserowitz, A. Global warming risk perceptions in India. Risk Anal. 2020, 40, 2481-2497. [CrossRef] [PubMed]

48. Neisi, M.; Bijani, M.; Abbasi, E.; Mahmoudi, H.; Azadi, H. Analyzing farmers' drought risk management behavior: Evidence from Iran. J. Hydrol. 2020, 590, 125243. [CrossRef]

49. Pakmehr, S.; Yazdanpanah, M.; Baradaran, M. How collective efficacy makes a difference in responses to water shortage T due to climate change in southwest Iran. Land Use Policy 2020, 99, 104798. [CrossRef]

50. Fahad, S.; Wang, J. Climate change, vulnerability, and its impacts in rural Pakistan: A review. Environ. Sci. Pollut. Res. 2020, 27, 1334-1338. [CrossRef]

51. Fourment, M.; Ferrer, M.; Barbeau, G.; Quénol, H. Local Perceptions, Vulnerability and Adaptive Responses to Climate Change and Variability in a Winegrowing Region in Uruguay. Environ. Manag. 2020, 66, 590-599. [CrossRef]

52. Smith, R.A. Risk perception and adaptive responses to climate change and climatic variability in northeastern St. Vincent. J. Environ. Stud. Sci. 2018, 8, 73-85. [CrossRef]

53. Hansen, J.W.; Marx, S.M.; Weber, E.U. The Role of Climate Perceptions, Expectations, and Forecasts in Farmer Decision Making: The Argentine Pampas and South Florida: Final Report of an Iri Seed Grant Project; International Research Institute for Climate Prediction: Palisades, NY, USA, 2004. [CrossRef]

54. Biesbroek, G.R.; Klostermann, J.E.M.; Termeer, C.J.A.M.; Kabat, P. On the nature of barriers to climate change adaptation. Reg. Environ. Chang. 2013, 13, 1119-1129. [CrossRef]

55. Chartzoulakis, K.; Bertaki, M. Sustainable water management in agriculture under climate change. Agric. Agric. Sci. Proc. 2015, 4, 88-98. [CrossRef] 
56. Wood, S.A.; Jina, A.S.; Jain, M.; Kristjanson, P.; DeFries, R.S. Smallholder farmer cropping decisions related to climate variability across multiple regions. Glob. Environ. Chang. 2014, 25, 163-172. [CrossRef]

57. Brody, S.; Grover, H.; Vedlitz, A. Examining the willingness of Americans to alter behaviour to mitigate climate change. Clim. Policy 2011, 12, 1-22. [CrossRef]

58. Hayashi, K.; Llorca, L.; Rustini, S.; Setyanto, P.; Zaini, Z. Reducing vulnerability of rainfed agriculture through seasonal climate predictions: A case study on the rainfed rice production in Southeast Asia. Agric. Syst. 2018, 162, 66-76. [CrossRef]

59. Niles, M.T.; Lubell, M.; Brown, M. How limiting factors drive agricultural adaptation to climate change. Agric. Ecosyst. Environ. 2015, 200, 178-185.

60. Berg, B.L. Qualitative Research Methods for the Social Sciences, 7th ed.; California State University: Long Beach, CA, USA, 2009.

61. Abera, N.; Tesema, D. Perceptions and practices of climate change adaptation and mitigation strategies among farmers in the Konta Special District, Ethiopia. Environ. Socio-Econ. Stud. 2019, 7, 1-16. [CrossRef]

62. Asrat, P.; Simane, B. Farmers' perception of climate change and adaptation strategies in the Dabus watershed, North-West Ethiopia. Ecol. Process. 2018, 7, 7. [CrossRef]

63. Bozzola, M.; Swanson, T. Policy implications of climate variability on agriculture: Water management in the Po river basin, Italy. Environ. Sci. Policy 2014, 43, 26-38. [CrossRef]

64. Fisher, A.P. Adapting and coping with climate change in temperate forests. Glob. Environ. Chang. 2019, 54, 160-171. [CrossRef]

65. Hill, M.; Engle, N.L. Adaptative capacity across scale. Environ. Policy Gov. 2014, 23, 177-192. [CrossRef]

66. Tinch, R.; Jäger, J.; Omann, I.; Harrison, P.A.; Wesely, J.; Dunford, R. Applying a capitals framework to measuring coping and adaptive capacity in integrated assessment models. Clim. Chang. 2015, 128, 323-337. [CrossRef]

67. Roco, L.; Engler, A.; Bravo-Ureta, B.E.; Jara-Rojas, R. Farmers' perception of climate change in mediterranean Chile. Reg. Environ. Chang. 2015, 15, 867-879. [CrossRef]

68. Joffre, O.M.; De Vries, J.R.; Klerkx, L.; Poortvliet, P.M. Why are cluster farmers adopting more aquaculture technologies and practices? The role of trust and interaction within shrimp farmers' networks in the Mekong Delta, Vietnam. Aquaculture 2020, 523, 735181. [CrossRef] 